ISS/EC 2009-01

\title{
Regulation Through a Revenue Contest
}

\author{
Haldun Evrenk and E. Ünal Zenginobuz
}

Ocak 2009

Sosyal Bilimler Enstitüsü

Boğaziçi Üniversitesi

34342 Bebek

İstanbul TURKEY

Boğaziçi Araştırma Raporları deneme

niteliğinde olup, bilimsel

tartışmaya katkı amacıyla

yayınlandıklarından, yazar(lar)ın

yazılı izni olmaksızın alıntı yapılamaz.
January 2009

Institute of Social Sciences

Boğaziçi Üniversitesi

34342 Bebek

İstanbul TURKEY

Boğaziçi Research Papers are of preliminary nature, circulated to promote scientific discussion. They are not to be quoted without written permission of the author(s). 


\title{
Regulation Through a Revenue Contest
}

\author{
Haldun Evrenk ${ }^{1}$ and E. Ünal Zenginobuz ${ }^{2}$
}

February 2, 2009

\footnotetext{
${ }^{1}$ Department of Economics, Suffolk University, 41 Temple St. Boston, MA USA $02108<$ hevrenk@suffolk.edu >

${ }^{2}$ Department of Economics and Center for Economic Design, Boğaziçi University, Istanbul, Turkey $34342,<$ zenginob@boun.edu.tr >
} 


\begin{abstract}
This paper proposes a mechanism for the regulation of duopolies: a revenue contests among the firms. Under the mechanism, the firm with the lower revenue is to pay a penalty to the firm with the higher revenue proportional to the difference between their revenues. In a homogenous good Cournot duopoly with convex cost and demand functions, the mechanism implements the optimal outcome when the firms have symmetric costs. When one firm is more efficient, the mechanism leads to increased social surplus under a large set of parameters.
\end{abstract}

KEY WORDS: oligopoly, regulation, yardstick competition, revenue contest

JEL CODES: D43, L13, L51 


\section{Introduction}

There has recently been a renewed interest in the theory of regulation for oligopolistic markets. ${ }^{1}$ This is partly due to the fact that many industries, once considered to be natural monopolies, are now organized in the form of oligopolistic structures. In more and more countries industries such as telecommunications, electricity supply, water supply, and health care now consist of multiple firms that are subjected to government regulation.

In this paper, we propose and study the properties of a simple mechanism for the regulation of oligopolistic industries. The mechanism involves instituting of a revenue contest among firms with a view to inducing them to expand their output over and above the level that would be obtained in the unregulated case. An appealing feature of the mechanism is its self-financing nature: the prize paid to the winners of the contest comes from the losers, and hence there is no need for outside funding of the prize. This avoids the problems associated with having to tax consumers to make payments to the firms, which will typically involve further costs and distortions as well as distributional concerns. In a wide variety of circumstances the mechanism leads to increased total social surplus (sum of consumers' and producers' surpluses) and hence ameliorates the efficiency performance of the imperfectly competitive industry.

The basic objective of a regulatory mechanism is to provide incentives, at a sufficiently low cost to the regulator, so that the firms in an imperfectly competitive industry expand their output beyond the level they would choose in the absence of regulation. In their muchcited work Loeb and Magat (1979) introduced a mechanism that can be used to induce a regulated monopoly to produce the efficient output, even if the regulator did not know the monopolist's costs. In their mechanism, the monopolist receives a subsidy equal to the increase in consumers' surplus that arises as the firm increases its output and lowers its price. This renders the monopolist's revenue function identical to the revenue function of a (perfectly) pricediscriminating monopolist, which will choose to produce the Pareto efficient level of output. Loeb and Magat (1979) did observe that the amount of subsidy necessary to implement their mechanism might be quite substantial and necessitate taxing of consumers, which typically

\footnotetext{
${ }^{1}$ See Mendoza-Contreras et al. (2008), Auriol and Picard (2008), Anton and Gertler (2004), Wang (2000), Sağlam (1997), Wolinsky (1997), Gradstein (1995), and Auriol and Laffont (1992). For earlier contributions to the theory of oligopoly regulation, see Koray and Sertel (1987, 1988, 1989), and Zenginobuz (1987). For a recent review of different strands of literature on regulating oligopolistic industries, see Armstrong and Sappington (2007).
} 
distorts efficiency. To resolve this difficulty, Loeb and Magat (1979) noted that one could auction the right to be the monopolist, and they claimed that the revenues from such an auction would be equal to the profits to be earned by the monopolist. ${ }^{2}$ Sharkey (1982) observed various difficulties with the implementation of the auction stage of Loeb and Magat's mechanism. Similarly, Bagnoli and Borenstein (1991) noted that in many realistic environments the Loeb and Magat auction scheme might not extract a substantial proportion of the profits. They contended that in situations where there is no viable competition for a firm, the Loeb and Magat scheme would not effectively extract any of the firm's profits, and thus would not benefit the consumers.

Gradstein (1995) adopted Loeb and Magat's idea of using subsidies as a regulatory device, and studied the implementation of the efficient outcome in an oligopoly through a decentralized mechanism that involves balanced transfers among firms. Balanced transfers avoid the problem of having to raise outside funds to provide incentives to firms to increase their output. In Gradstein's scheme transfers among firms are determined as a function of all firms' output choices. Gradstein did not consider a particular balanced transfer scheme among firms; instead he studied, in a specific environment, the more general question of implementability of the efficient outcome through balanced transfer schemes. ${ }^{3}$

The revenue contest that this paper proposes as a regulatory mechanism for oligopolies can be viewed as particular balanced transfer scheme in which the payment to one firm depends on the actions of other firms as well as its own actions. The proposed mechanism will work under a variety of informational assumptions on the part of the regulator and for different specifications regarding the nature of competition between the firms (Evrenk, 1999). To better elucidate the nature of the proposed mechanism, here we concentrate on a Cournot duopoly game under complete information.

The mechanism works as follows: after a production period the regulator compares the revenues of the two firms and makes the firm with the lower revenue pay a penalty to the firm with higher revenue. The penalty that the firm with the lower revenue pays is taken to

\footnotetext{
${ }^{2}$ The proposal by Loeb and Magat (1979) is along the lines of the proposal put forward by Demsetz (1968), who suggested that monopoly franchises should be awarded to the firms that demonstrate they will produce the maximum consumer surplus.

${ }^{3}$ In an environment where demand is known and there is no information regarding the firms' costs, and restricting the set of admissable demand and cost functions such that all firms produce positive amounts of output, Gradstein showed that the efficient outcome is implementable if the demand function is a polynomial of at most $(n-1)$ th degree, where $n$ is the number of firms in the industry.
} 
be a linear function of the difference between the revenues. Since both the reward and the penalty increases with the difference between revenues, both firms are induced to increase their output. The more a firm produces the higher the prize it gets if it ends up winning the contest, and the lower the penalty it pays if it ends up losing the contest. Thus, the total output will increase, leading to lower market price, higher consumers' surplus, and lower producers' surplus. An important feature of this regulatory scheme is that the increase in consumers' surplus will exceed the fall in producers' surplus, and hence total welfare will be increased. The proposed scheme does not yield, however, first-best outcomes except in the special case of symmetric cost structure for firms.

A line of literature that considers relative performance evaluation in oligopolistic industries is the literature on "yardstick competition". 4 Since costs of firms producing under similar conditions will typically be correlated, a regulator may be able to establish industry standards against which to measure the performance of each individual firm. Through such relative performance evaluations it might be possible to extract rents and increase production efficiency in industries. A possible problem with yardstick competition in oligopolistic industries is the creation of further incentives for collusion. As they are played out against each other one would expect the regulated firms to look more aggressively for ways to collude. ${ }^{5}$ We investigated whether our revenue contest mechanism leads to a more collusive behavior on the part of the duopolists. Under both linear demand and constant elasticity demand, we checked the impact of the mechanism on incentives to collude in the standard framework of infinitely repeated games with trigger strategies. In a linear duopoly, the incentives to collude does not increase although the firms make zero profit when regulated. When the price elasticity of demand is constant, the incentives to collude increases but only slightly.

The paper closest to ours is that of Bagnoli and Borenstein (1991), who considered an output contest among firms as a regulatory mechanism for oligopolistic industries. ${ }^{6}$ They proposed instituting a regulatory scheme in which a constant money prize is offered to the firms that will be divided between them in a manner that depends on the output produced by each. As in our

\footnotetext{
${ }^{4}$ See Shleifer (1985), Auriol and Laffont (1992), and Sobel (1999) for applications to regulation.

${ }^{5}$ For a study on optimal yardstick competition under the threat of collusion, see Tangerås (2002).

${ }^{6}$ Dixit (1987) mentions the case of oligopolistic competition for a homegenous good with unit-elastic demand, where firms compete for market share through spending resources. An earlier work along similar lines is by Schmalensee (1976), where he studies a differentiated goods model in which firms compete for market revenue through advertising expenditures.
} 
paper, their regulator induces competition through making the prize that a firm receives depend on both its own output and the output of other firms. They show, through simulations for a wide range of plausible demand and cost parameters (constant elasticity demand and constant marginal cost) that their scheme increases consumer surplus by more than the total prize. As our mechanism, their scheme also does not yield first-best outcomes.

Though similar in spirit, in the sense of relying on relative rather than absolute criteria in assessing regulatory performance, our mechanism differs from the scheme proposed by Bagnoli and Borenstein in two respects. The most important distinction is that the output prize in Bagnoli and Borenstein's scheme has to be funded from outside, whereas our scheme is selffinanced. Bagnoli and Borenstein stated that the consumers would have to put up the funds for output price, and recognized that the cost and distortion from collecting the funds for the prize is an important issue in any discussion of a regulatory scheme that involves payments to the firms. ${ }^{7}$ The second distinction relates to the nature of the object that is compared in each scheme. In their scheme quantities of output are compared. In ours the output levels are converted to a quantity in common units (revenue in monetary units) before the comparison. This renders our scheme directly applicable to differentiated product industries, whereas in theirs a conversion scale would have to be added to the scheme in order to compare quantities of different goods.

Though not typically associated with theory of regulation, another line of literature that has bearing on the regulatory mechanism studied in this paper is the "managerial incentives", or the "strategic delegation" literature. Drawing on the insight that in strategic environments a principal may gain additional advantage by hiring an agent and giving him incentive to maximize an objective function different than the principal's payoff function, Fershtman and Judd (1987) and Sklivas (1987) provided models where they demonstrated that an owner of a firm in an oligopolistic industry may earn a larger profit if he hires a manager and, through an appropriately chosen incentive scheme, induces him to maximize a weighted average of sales and profits. ${ }^{8}$ The regulation problem, as treated in this paper, can in fact be viewed along similar

\footnotetext{
${ }^{7}$ Though there is no agreement on the value of the cost of public funds, Laffont (1996) mentions values as high as 2.48 U.S. dollars for developing countries. This means that one dollar rent paid to the regulated firms ends up costing the taxpayers 3.48 U.S. dollars.

${ }^{8}$ More recently, Krakel (2005) combines the strategic delegation approach with an oligopolistic contest and studies how the optimal combination of sales and profits as incentives for managers will change if the managers compete in an oligopolistic tournament (contest) against each other.
} 
lines as the problem of assigning by the regulator (the principal) an appropriate objective function to the regulated firms (the agents). By enforcing a revenue contest on the industry the regulator indeed changes the objective functions of the firms and, as a consequence, induces more competition and hence enhanced industry performance.

The paper is organized as follows. Section 2 introduces the model studied, and provides preliminary analyses towards identifying equilibria. Section 3 first studies the effectiveness of the mechanism in increasing the social surplus and reaching efficient outcomes. Then, it provides an analysis of the effects of the mechanism on incentives to collude in an infinitely repeated game setting. Section 4 summarizes and discusses the results obtained and provides concluding remarks.

\section{The Model}

Consider a Cournot model of duopoly that the government might regulate. ${ }^{9}$ Let $x_{i} \geq 0$ denote the output level, $C_{i}\left(x_{i}\right)$ denote the cost function, and $R_{i}\left(x_{i}, x_{j}\right)=P(X) x_{i}$ denote the total revenue of firm $i$, where $i \in\{1,2\}$. Let $P(X)$ denote the inverse demand function, where $X=x_{1}+x_{2}$ is the total output level, and let $\eta(X)=\frac{P(X)}{P^{\prime}(X) X}$ denote the price elasticity of demand at output level $X$. We assume that the (inverse) demand is continuos and differentiable and that when $P(X)>0$,

A1) it is decreasing, $P^{\prime}(X)<0$;

A2) it is convex, $P^{\prime \prime}(X) \geq 0$;

A3) the marginal revenue is a decreasing function of the output, $P^{\prime \prime}(X) X+2 P^{\prime}(X)<0$.

We also we assume that

A4) each firm's cost function is convex, $C_{i}^{\prime}\left(x_{i}\right)>0, C_{i}^{\prime \prime}\left(x_{i}\right) \geq 0$.

In this setup, we study the subgame-perfect equilibrium of a two-stage game. The regulator moves first, it chooses the specifics of its regulatory policy and announces this policy to the firms before they make their output decisions. The objective of the regulator is to maximize

\footnotetext{
${ }^{9}$ The model can be generalized to oligopolies with more than two firms, but a duopoly setup is sufficient to expose the basic features of the mechanism studied with minimal notation. Note also that we abstract from the reasons why a government might want to regulate an oligopoly. See Armstrong and Sappington (2007) for a review of reasons for implementing regulation in oligopoly settings.
} 
the social surplus, $S S\left(x_{1}, x_{2}\right)$, defined as the sum of consumers' surplus and producers' surplus,

$$
\int_{0}^{x_{1}+x_{2}} P(y) d y-P\left(x_{1}+x_{2}\right) \cdot\left(x_{1}+x_{2}\right)+\sum_{i \in\{1,2\}} \Pi_{i}\left(x_{i}, x_{j}\right)
$$

where $\Pi_{i}\left(x_{i}, x_{j}\right)=P(X) x_{i}-C_{i}\left(x_{i}\right)$. In the second stage the firms choose their output with the full knowledge of the regulatory policy. The regulatory policy we consider is a revenue contest.

The rules for the revenue contest are simple: the firm with the lower revenue is required to pay a penalty, which we will take to be a linear function of the difference of the revenues of the two firms, to the firm with the higher revenue. Thus, when regulated, firm $i$ 's total payoffs will be

$$
\Pi_{i}^{r}\left(x_{i}, x_{j}, \theta\right)=\Pi_{i}\left(x_{i}, x_{j}\right)+\theta\left[R_{i}\left(x_{i}, x_{j}\right)-R_{j}\left(x_{i}, x_{j}\right)\right]
$$

where $\theta \geq 0$ is the revenue contest parameter, set and announced by the regulator. After the market outcomes are realized, the regulator will enforce the outcome of the mechanism through assessing the rewards and the penalties the mechanism calls for and it will make sure (enforce) that the necessary transfers are made. Therefore, for a given $\theta>0$, the firms will be engaged in a game where each firm's payoff depend partly on its relative performance with respect to its competitor.

To simplify the analysis we study this as a complete information game. ${ }^{10}$ That is, when choosing their output levels, the firms know their own costs as well the costs of their rivals and the demand for their product; and, when choosing the contest parameter, the regulator has complete information regarding the industry structure (i.e., $P(X)$ and $C_{i}($, )'s for each firm i). ${ }^{11}$ When it comes to enforce the mechanism, we assume that the amount of output produced by firm $i$ is verifiable. We also assume that all fixed cost is sunk. ${ }^{12}$ Finally, since our interest will be confined to active duopolies, we assume at the outset that the parameters of the game are such that each firm's output will be positive in the unique pure strategy Nash Equilibrium

\footnotetext{
${ }^{10}$ In a linear setup (and, for a wide in set of parameters) Evrenk (1999) shows that a less than fully informed regulator can increase the social surplus by using the mechanism in Cournot and Stackelberg models as well as in a differentiated goods model of duopoly.

${ }^{11}$ As the informational asymmetry between the firms is not the issue here (and, as this assumption considerably simplifies the analysis), we assume that firms compete in a complete information game. Though unrealistic, the fully informed regulator case is studied because it allows a clear exposition of the logic of the mechanism proposed and the conditions under which it will enhance industry performance. As we discuss following Proposition 1, under certain conditions, all the regulator needs to know is the price elasticiy of demand at a certain point.

${ }^{12}$ So that, the socially optimal output levels can be defined in terms of the marginal costs only.
} 
(PSNE) of the unregulated Cournot duopoly. ${ }^{13}$ The exact nature of assumptions that will allow this will be made explicit in the statement of the results below.

Solving the game in standard backward fashion, for a given $x_{j}$ and $\theta$, firm $i$ chooses $x_{i}$ to maximize $\Pi_{i}^{r}\left(x_{i}, x_{j}, \theta\right)$. Its associated first order condition is given by

$$
(1+\theta) P\left(x_{i}+x_{j}\right)+P^{\prime}\left(x_{i}+x_{j}\right)\left(x_{i}+\left(x_{i}-x_{j}\right) \theta\right)-C_{i}^{\prime}\left(x_{i}\right) \leq 0\left(=0 \text { when } x_{i}>0\right) .
$$

As we prove in the Appendix,

Lemma 1 In the relevant part of the strategy space, $\Pi_{i}^{r}\left(x_{i}, x_{j}, \theta\right)$ is strictly quasi-concave in $x_{i}$; i.e., (3) implicitly defines a best-response function, $B_{i}\left(x_{j}, \theta\right)$, for each $i$. When $B_{i}\left(x_{j}, \theta\right)>0$, we have $\frac{\partial B_{i}\left(x_{j}, \theta\right)}{\partial \theta}>0$.

Intuitively by changing the firm's objective function into (2), the regulator raises each firm's marginal revenue. To maximize its profit, each firm produces an output level under which its marginal revenue is equal to its marginal cost. The marginal cost is not decreasing in output, thus, a shift in marginal revenue shifts the best-response function. Less formally, the incentives the mechanism offers to firms to increase their output involves both a carrot and a stick. When $\theta$ increases, a firm produces more not only to win the prize, but also to reduce the penalty it will pay in the case it loses the contest.

\section{The effectiveness of the mechanism}

In this section, we first examine the effectiveness of the mechanism in enhancing social surplus in both symmetric and asymmetric duopolies. Then, we consider the effects of the mechanism on duopolists' incentives to collude using "trigger strategies" in an infinitely repeated duopoly.

\subsection{The mechanism in a symmetric duopoly}

When the firms have the same level of efficiency, $C_{1}^{\prime}(x)=C_{2}^{\prime}(x)=C^{\prime}(x)$, in the equilibrium of unregulated Cournot duopoly each firm's mark-up ratio will be as follows:

$$
\frac{P\left(X^{*}\right)-C^{\prime}\left(X^{*} / 2\right)}{P\left(X^{*}\right)}=-\frac{1}{2 \eta\left(X^{*}\right)} .
$$

\footnotetext{
${ }^{13}$ With or without regulation, we ignore the possibility that a firm may play a mixed strategy.
} 
Using (3), it is straightforward to show that under the revenue contest when each firm produces $X^{*}(\theta) / 2$ the mark-up ratio is given by

$$
\frac{P\left(X^{*}(\theta)\right)-C^{\prime}\left(X^{*}(\theta) / 2\right)}{P\left(X^{*}(\theta)\right)}=\frac{-1}{2 \eta\left(X^{*}(\theta)\right)}-\theta
$$

The social surplus is maximum when each firm produces the output level $\frac{X^{o}}{2}$, which is implicitly defined by

$$
P\left(X^{o}\right)=C^{\prime}\left(X^{o} / 2\right)
$$

When each firm produces $\frac{X^{o}}{2}$, the mark-up ratio is equal to zero for both firms. The regulator can accomplish this outcome by using the revenue contest.

Proposition 1 When there is no efficiency difference between the firms, the regulator can always induce the first-best output levels by setting $\theta=\frac{-1}{2 \eta\left(X^{\circ}\right)}$.

In the Appendix, we prove Proposition 1 by showing that when the revenue contest parameter is equal to $\frac{-1}{2 \eta\left(X^{\circ}\right)}$, the game has a unique pure strategy Nash Equilibrium (PSNE) in which each firm produces $\frac{X^{o}}{2}$. Let us note some important properties of the mechanism. First, to implement the socially optimal output levels, all the regulator needs to know is the price elasticity of demand at the optimal output level $X^{o}$. When the price elasticity of demand is constant, say $\eta(X)=-\varepsilon$ at all $X$, the regulator does not need any data on the cost function; then, the optimal contest parameter is simply equal to $\frac{1}{2 \varepsilon}$. When the price elasticity of demand differs at each output level, the regulator must know the marginal cost function to calculate the optimal output level, $X^{o}$. For instance, when the inverse demand is linear, $P(X)=a-X$, and the marginal cost is constant, $C^{\prime}(x)=c$, the optimal contest parameter is given by $\frac{a-c}{2 c}$. Also note that if the price elasticity of demand decreases in total output, then the more efficient the firms are, the higher will be the optimal output, implying an higher optimal contest parameter.

Second, under the mechanism the profits are lower compared to the profits in the unregulated Cournot duopoly. ${ }^{14}$ In other words, the mechanism not only increases the social surplus, but it also transfers some of the original producers' surplus to consumers. For simplicity, in this

\footnotetext{
${ }^{14}$ That is, $P\left(X^{o}\right) X^{o} / 2-C\left(X^{o} / 2\right)<P\left(X^{N}\right) X^{N} / 2-C\left(X^{N} / 2\right)$ where $X^{N}$ is the aggregate output in unregulated Cournot duopoly. To see why, note that under any $\theta \geq 0$, (4) implies that $\frac{P(X)-C^{\prime}(X / 2)}{P(X)}<-\frac{P^{\prime}(X) X}{P(X)}=\frac{-1}{\eta(X)}$. This is a sufficient condition under which the firm's profit level in the symmetric equilibrium, $P\left(X^{*}(\theta)\right) X^{*}(\theta) / 2-$ $C\left(X^{*}(\theta) / 2\right)$, is decreasing in $X^{*}(\theta)$. Since $X^{N}<X^{o}$, each firm's profit will decrease when they produce the socially optimal output levels.
} 
paper we assume that the regulator weighs the consumers' and producers' surplus equally, but when one considers a regulator who puts a higher weight on a gain in consumers' surplus, as in Baron and Myerson (1982), this is an especially desirable property.

Third, with identical firms, the optimal contest parameter will induce each firm to produce half of the socially optimal output level. With each firm producing the same output, the contest will not have a loser or a winner; neither firm will pay any penalty. Given our assumption that the fixed cost is sunk and that the cost function is convex, the overall profits of each firm will be non-negative in equilibrium. Therefore, in a symmetric duopoly each duopolist's profit is high enough to keep the firm participating when they produce first-best output levels. We show in the next section that this is not necessarily the case in an asymmetric duopoly.

\subsection{The mechanism in an asymmetric duopoly}

Assume, without loss of generality, that Firm 1 is the more efficient firm, $C_{1}^{\prime}(x)<C_{2}^{\prime}(x)$ for all $x \in R_{+}$. When the firms differ in their efficiency, the social optimum involves either each firm producing $x_{i}^{o}$ units, where $C_{i}^{\prime}\left(x_{i}^{o}\right)=P\left(x_{1}^{o}+x_{2}^{o}\right)$ for each firm $i$; or only the efficient firm producing $\widetilde{x}_{1}^{o}$, where $C_{1}^{\prime}\left(\widetilde{x}_{1}^{o}\right)=P\left(\widetilde{x}_{1}^{o}\right)<C_{2}^{\prime}(0)$. The former will be the case, for instance, when the marginal cost is increasing, $C_{i}\left(x_{i}\right)=c_{i} x_{i}^{2}$, and the latter will be the case, for instance, when the marginal cost is constant, $C_{i}\left(x_{i}\right)=c_{i} x_{i}$. If it involves only a single firm, the social optimum cannot be implemented through a revenue contest. A contest is possible only when both firms are active. When Firm 2 is not producing, yet, it is forced to pay the penalty, its participation constraint is violated: it will leave the market altogether to avoid the penalty.

Even if both firms must produce in the social optimum, the socially optimal output combination in an asymmetric duopoly cannot be implemented through a revenue contest. In this case, the participation constraint of the firms are not necessarily violated. What prevents the regulator from implementing the optimal output levels is that there is always a discrepancy between the output patterns that the regulator can implement using the contest and the socially optimal output pattern. The socially optimal output levels satisfy both of the following conditions: $x_{1}^{o}>x_{2}^{o}$ and $C_{1}^{\prime}\left(x_{1}^{o}\right)=C_{2}^{\prime}\left(x_{2}^{o}\right)=P\left(x_{1}^{o}+x_{2}^{o}\right)$. The equilibrium output and marginal cost pattern in an asymmetric Cournot duopoly regulated through a revenue contest, are as follows:

Lemma 2 The winner of the contest is always the more efficient firm, $x_{1}^{*}(\theta)>x_{2}^{*}(\theta)$. In 
equilibrium, the winner's marginal cost is always smaller than that of the loser, $C_{1}^{\prime}\left(x_{1}^{*}(\theta)\right)<$ $C_{2}^{\prime}\left(x_{2}^{*}(\theta)\right)$.

We prove Lemma 2 in the Appendix. In an unregulated Cournot duopoly, too, when the firms differ in their effectiveness, equilibrium output levels, marginal revenues, and, their marginal costs will differ among firms (Tirole, 1997, p. 219). The intuition is the same: the firms will have the same marginal cost in equilibrium only when their marginal revenues are the same. Their marginal revenues are the same only when they produce the same output level. Yet, since they differ in their efficiencies, when their output levels is the same, their marginal costs will differ. Therefore, using the revenue contest the regulator cannot induce an equilibrium in which the equilibrium marginal costs of the firms are the same but they produce different output levels.

To summarize,

Proposition 2 When firms differ in their efficiency, the first-best output level is not attainable through the revenue contest.

We provide a formal proof for Proposition 2 in the Appendix. In the rest of this section, we show that under plausible cost and demand parameters the regulator will still be able to increase social surplus by using the revenue contest mechanism. That is, under a wide set of parameters, the regulator will set the contest parameter larger than zero, $\theta^{*}>0$.

The equilibrium of unregulated Cournot Duopoly is a special case of the revenue contest with $\theta=0$. A sufficient condition under which the regulator can implement a second-best by using the contest is that $\left.\frac{d S S\left(x_{1}^{*}(\theta), x_{2}^{*}(\theta)\right)}{d \theta}\right|_{\theta=0}>0$. For a general $\theta$, the effect of an infinitesimal increase in $\theta$ on social surplus, $\frac{d S S\left(x_{1}^{*}(\theta), x_{2}^{*}(\theta)\right)}{d \theta}$, is give by

$$
\left(P\left(X^{*}(\theta)\right)-C_{1}^{\prime}\left(x_{1}^{*}(\theta)\right)\right) \frac{d x_{1}^{*}(\theta)}{d \theta}+\left(P\left(X^{*}(\theta)\right)-C_{2}^{\prime}\left(x_{2}^{*}(\theta)\right)\right) \frac{d x_{2}^{*}(\theta)}{d \theta},
$$

where $X^{*}(\theta)=x_{1}^{*}(\theta)+x_{2}^{*}(\theta)$. When both firms are active in the unregulated Cournot duopoly $\left(x_{1}^{*}(0)>x_{2}^{*}(0)>0\right)$ and the participation constraint is not binding for either firm ${ }^{15}$, we will have $P\left(X^{*}(\theta)\right)-C_{i}^{\prime}\left(x_{i}^{*}(\theta)>0\right.$ for both $i$. Then, the optimal contest parameter is always larger than zero, if, for instance, the output of both firms increases in $\theta$. At this level of generality

\footnotetext{
${ }^{15}$ That is, at $\theta=0$, we have $\Pi_{i}^{r}\left(x_{i}^{*}(\theta), x_{j}^{*}(\theta), \theta\right)>0$ for each $i \in\{1,2\}$.
} 
we cannot guarantee this condition; all we can say is that an increase in $\theta$ results in a higher aggregate output.

Lemma 3 As long as the participation constraints hold for each firm, the aggregate output always increases in $\theta, \frac{d X^{*}(\theta)}{d \theta}=\frac{d x_{1}^{*}(\theta)}{d \theta}+\frac{d x_{2}^{*}(\theta)}{d \theta}>0$.

Lemma 3 implies that if the efficient firm's output increases in the contest parameter, then we always have $\left.\frac{d S S\left(x_{1}^{*}(\theta), x_{2}^{*}(\theta)\right)}{d \theta}\right|_{\theta=0}>0$, and, thus, $\theta^{*}>0 .{ }^{16}$ Using the fact that the mark-up ratio for $i$ in equilibrium of the unregulated Cournot duopoly is equal to $\frac{s_{i}}{\eta\left(X^{*}\right)}$, where $s_{i}$ is the market share of firm $i$, we can write $\left.\frac{d S S\left(x_{1}^{*}(\theta), x_{2}^{*}(\theta)\right)}{d \theta}\right|_{\theta=0}>0$ also as ${ }^{17}$

$$
\left(s_{1}-s_{2}\right) \frac{d x_{1}^{*}(\theta)}{d \theta}+s_{2} \frac{d X^{*}(\theta)}{d \theta}>0
$$

evaluated at $\theta=0$. None of these sufficient conditions will always hold ${ }^{18}$, it is possible to find examples in which the efficient firm's market share is large enough and that its output decreases sufficiently in $\theta$ so that $\left.\frac{d S S\left(x_{1}^{*}(\theta), x_{2}^{*}(\theta)\right)}{d \theta}\right|_{\theta=0}<0$. Without further assumptions on the cost and demand functions, we cannot determine when (6) is violated. (In Appendix B, we discuss the sufficient conditions on best-response functions under which the efficient firm's output always increases in $\theta$.) When we know that (6) does hold, we know that $\theta^{*}>0$. Below we calculate the optimal $\theta$ for two commonly used demand functions. To simplify the calculations, in both examples we assume that each firm has constant marginal cost, $C_{i}\left(x_{i}\right)=c_{i} x_{i}$ and $c_{1}<c_{2} .{ }^{19}$

Example 1: Assume, as in Bagnoli and Borenstein (1991), that $P(X)=A X^{-\eta}$, where $A>0$ and $\eta>1$. In this setup, one can show analytically that (i) the unregulated Cournot duopoly has a unique PSNE in which both firms are active if and only if $c_{1} \geq\left(1-\frac{1}{\eta}\right) c_{2}$, and (ii) under the revenue contest there exists a unique equilibrium and in this equilibrium both firms are active as long as the condition in (i) holds. More importantly, under the constant elasticity

\footnotetext{
${ }^{16}$ Because by Lemma 2 , we always have $P\left(X^{*}(\theta)\right)-C_{1}^{\prime}\left(x_{1}^{*}(\theta)\right)>P\left(X^{*}(\theta)\right)-C_{2}^{\prime}\left(x_{2}^{*}(\theta)\right)$ at $\theta=0$.

${ }^{17}$ The middle step is $-\frac{P\left(X^{*}\right)}{\eta\left(X^{*}\right)}\left(s_{1} \frac{d x_{1}^{*}(\theta)}{d \theta}+s_{2} \frac{d x_{2}^{*}(\theta)}{d \theta}\right)>0$.

${ }^{18}$ By using (3) and the derivations for $\frac{d x_{i}^{*}(\theta)}{d \theta}$ 's from the proof of Lemma 3, we can also write the condition $\left.\frac{d S S\left(x_{1}^{*}(\theta), x_{2}^{*}(\theta)\right)}{d \theta}\right|_{\theta=0}<0$ in a way that does not include $\theta$, i.e.,

$$
\frac{P\left(X^{*}\right)}{P^{\prime}\left(X^{*}\right)\left(x_{2}^{*}-x_{1}^{*}\right)}>\frac{3 P^{\prime}\left(X^{*}\right)\left(x_{2}^{*}-x_{1}^{*}\right)+P^{\prime \prime}\left(X^{*}\right)\left(x_{2}^{*}+x_{1}^{*}\right)\left(x_{2}^{*}-x_{1}^{*}\right)+x_{1}^{*} C_{2}^{\prime \prime}\left(x_{2}^{*}\right)+x_{2}^{*} C_{1}^{\prime \prime}\left(x_{1}^{*}\right)}{-P^{\prime}\left(X^{*}\right)\left(x_{1}^{*}+x_{2}^{*}\right)+P^{\prime \prime}\left(X^{*}\right)\left(x_{1}^{*}-x_{2}^{*}\right)^{2}+x_{1}^{*} C_{2}^{\prime \prime}\left(x_{2}^{*}\right)+x_{2}^{*} C_{1}^{\prime \prime}\left(x_{1}^{*}\right)} .
$$

where $X^{*}, x_{1}^{*}$ and $x_{2}^{*}$ are equilibrium output levels in the unregulated Cournot duopoly.

${ }^{19}$ In Appendix C, we provide the equilibrium output levels and a brief discusssion. Complete analytical solutions for both examples as well as the Mathematica notebooks for the simulations are available upon request.
} 
demand, we always have $\frac{d S S\left(x_{1}^{*}(\theta), x_{2}^{*}(\theta)\right)}{d \theta}>0 .{ }^{20}$ Therefore, the optimal contest parameter is easy to calculate: to maximize the social surplus the regulator must set the contest parameter so that the participation constraint for Firm 2 is just binding, $\Pi_{2}^{r}\left(x_{i}^{*}(\theta), x_{j}^{*}(\theta), \theta\right)=0$. The value of the optimal contest parameter and the percentage increase in the social surplus due to regulation are presented in Figure 1, panels (a) and (b), respectively.

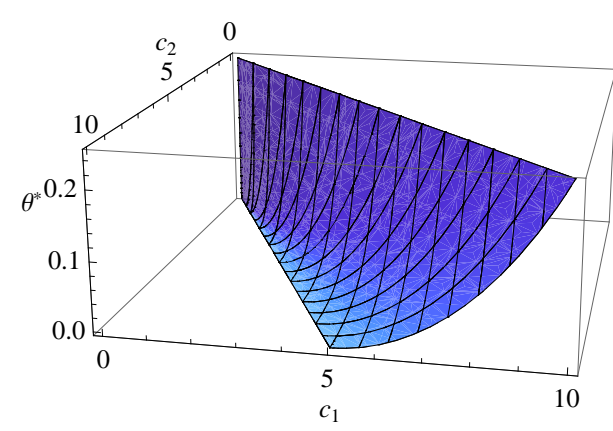

(a)

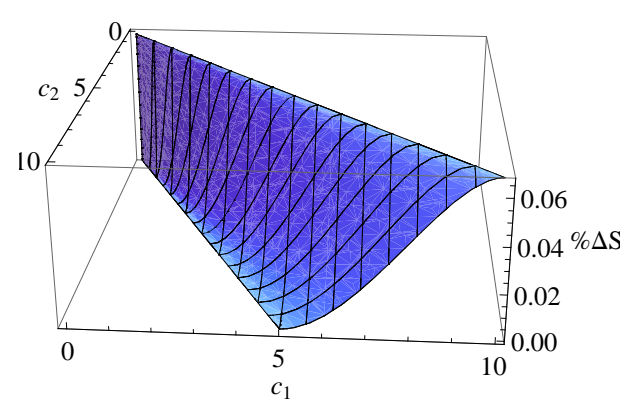

(b)

Figure 1: The optimal contest parameter, panel (a), and the percentage increase in social surplus under regulation, panel (b), when the inerse demand is equal to $1 / X^{2}$.

In calculating these figures we set $\eta=2$ (so, when $c_{1}=c_{2}$, the optimal contest parameter is equal to $\frac{1}{4}$ ) and we consider values of $c_{1}$ in the interval $[0,10]$. But, both the optimal contest parameter and the percentage increase in social surplus due to regulation depend only on the ratio of marginal costs and this result holds under any $\eta>1$. Under a larger (smaller) $\eta$, the optimal contest parameter is smaller (larger) and the percentage social surplus gain due to revenue contest regulation is larger (smaller). In calculating these figures, we also set $A=1$, but, again, neither the optimal contest parameter nor the percentage increase in social surplus depends on $A$.

Example 2: $P(X)=a-X$, where $a>0$. The unregulated Cournot duopoly has a unique equilibrium, and in this equilibrium both firms are active, when $a+c_{1} \geq 2 c_{2}$. The area between the two thick lines in Figure 2.a corresponds to the set of parameters under which this condition holds. Unlike the constant demand case, when demand is linear (6) may not hold: it

\footnotetext{
${ }^{20}$ This is due to the fact that when the demand is constant elastic, the efficient firm's best-response function is always increasing in $x_{2}$; see Appendix B.
} 
is straightforward to show that only when

$$
c_{1}>\frac{a+52 c_{2}-3 \sqrt{25 a^{2}+24 a c_{2}-48 c_{2}^{2}}}{56}
$$

does (6) hold. The thick curve in Figure 2.b is the boundary for (7), i.e., when he marginal cost of the firms fall above this curve, the regulator will always use the revenue contest mechanism. Further, one can also show that when

$$
c_{1}>\frac{8 c_{2}-a}{10}
$$

the efficient firm's output, and, thus, the social surplus always increases in $\theta$. Inequality (8) is a sufficient condition under which the optimal contest parameter simply solves for $\Pi_{2}^{r}\left(x_{i}^{*}(\theta), x_{j}^{*}(\theta), \theta\right)=0$. In Figure 2.b, (8) holds above the thick line. Also note that when the inefficient firm's marginal cost exceeds $\frac{3 a}{4}$, both (7) and (8) hold in the set of parameters under which the unregulated Cournot duopoly exists. In Figure 2, panels (c) and (d), we plot both the optimal $\theta$ and the percentage increase in social surplus when (8) holds. Note that when both marginal cost parameters go to zero, the optimal $\theta$ goes to infinity, so the graph in Figure 2.c is truncated from above.

When (7) holds but (8) fails to hold the optimal contest parameter has to be calculated in a case-by-case basis: under the linear demand the social surplus is a long third-degree polynomial in $\theta$, and, depending on the numerical value of $a$, the optimal $\theta$ may not be the one that makes the inefficient firm's participation constraint just binding. More interesting is what may happen when neither (8) nor (7) holds.

In a linear Cournot duopoly, it is possible that the social surplus is always decreasing in $\theta$. Point $\mathbf{E}$ in Figure 2.b would correspond to such a parameter vector $\left(a=16, c_{1}=1, c_{2}=7\right)$. Under these parameters, the unregulated Cournot duopoly has a unique equilibrium. In this equilibrium the output levels are $(7,1)$, thus, the market shares are $(7 / 8,1 / 8)$, and the profit levels are $(49,1)$ for Firms 1 and 2. The inefficient firm's participation constraint is satisfied only when $\theta<0.023$. In this interval, the aggregate output increases, but, the efficient firm's output always decreases. The increase in aggregate output does not increase social welfare as this increase happens at the cost of reallocating some output from efficient Firm 1 to the inefficient Firm 2 when the former is seven times more efficient than the latter. Therefore, in 


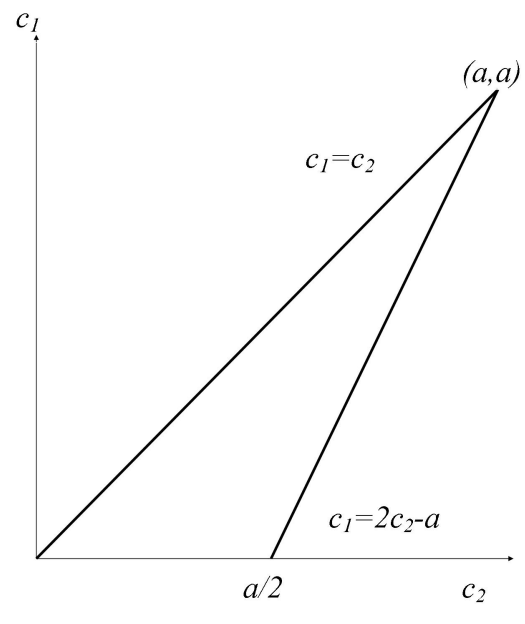

(a)

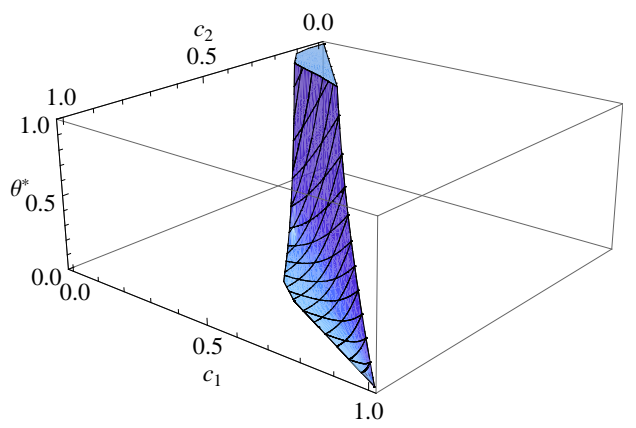

(c)

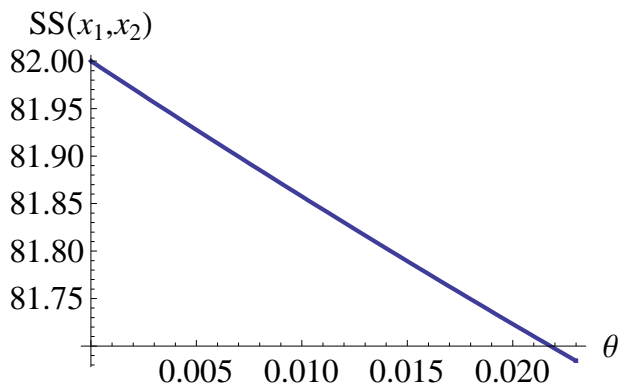

(e)

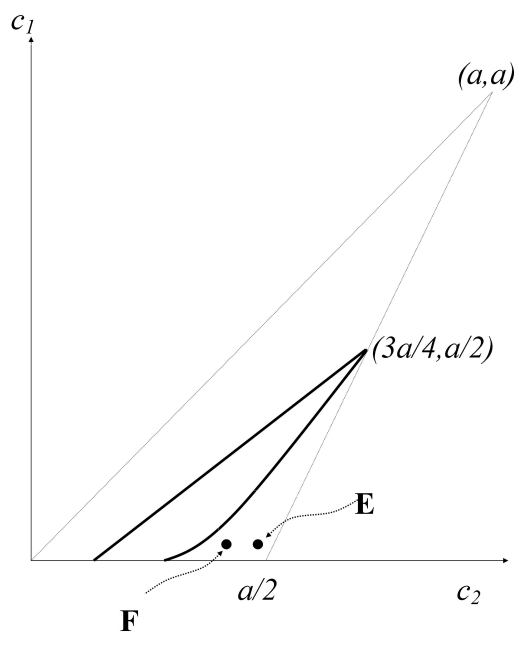

(b)

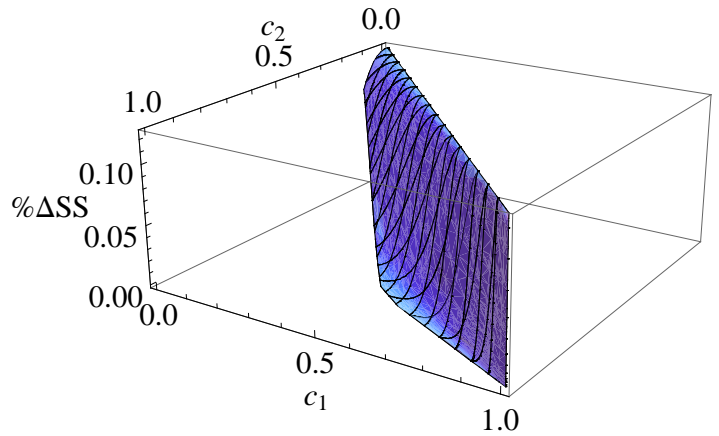

(d)

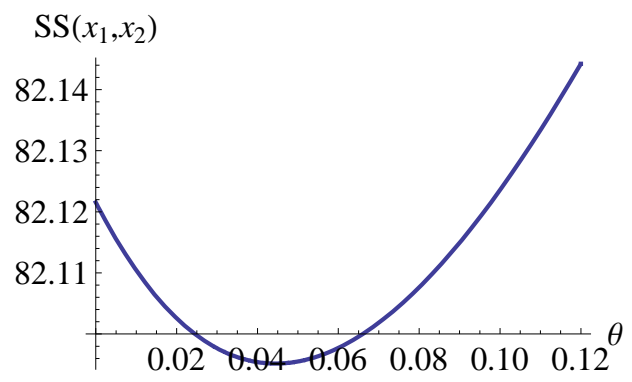

(f)

Figure 2: Only if the parameters of the model lie between the two thick lines in (a), a unique interior equilibrium exists in unregulated Cournot duopoly. The thick curve and the thick line in panel (b) represents (7) and (8) when binding. Optimal contest parameter and percentage increase in social surplus when $P(X)=1-X$ and (8) holds are presented in panels (c) and (d). Panels (e) and (f) plot social surplus as a function of $\theta$ at points $\mathbf{E}$ and $\mathbf{F}$ in panel (b). 
(5) the weight on the output loss by the efficient firm, $P(X)-1$, is at least seven times larger than the weight on the output gain by the inefficient firm, $P(X)-7$. As a results, the social surplus is a monotone decreasing function of $\theta$ in the interval [0,0.023]: the socially optimal $\theta$ is equal to zero. Intuitively, at $\mathbf{E}$, compared to the size of the market the cost difference between the firms is very large.

Condition (8) rules out underproduction by the efficient firm while (7) rules out too much underproduction by the efficient firm. ${ }^{21}$ Both conditions basically restrict the efficiency difference between the firms (relative to the market size). However, both conditions are sufficient not necessary. To see that the revenue contest could still increase the social surplus even when neither of these conditions hold, consider point $\mathbf{F}$, where the parameters $a$ and $c_{1}$ are the same as those in $\mathbf{E}$, but the inefficient firm is slightly more efficient, $c_{2}=5.75$. At $\mathbf{F}$, too, the social surplus first decreases in $\theta$. But, due to lesser efficiency difference between the firms in this case, Firm 2 will stay in the market as long as $\theta \leq 0.12$. The social surplus eventually increases and at $\theta=0.12$, it is larger than the social surplus in the unregulated duopoly. As the social surplus is a long third degree polynomial in $\theta$, it is difficult to calculate analytically the exact point at which it may change sign for a general set of parameters.

\subsection{Effects on the incentives to collude}

In a Cournot duopoly, industry wide profits are not maximal; for maximal industry wide profit the total industry production must be at the monopoly production level, $X^{M}$. But, when total output level is equal to $X^{M}$, each duopolist has an incentive to increase its production, which in turn yields higher output and lower profits for the industry. On the other hand, Freidman (1971) shows that in a infinitely repeated Cournot duopoly, cooperation among duopolists for maximal industry wide profit may be achieved with trigger strategies for a set of discount parameters. More formally, in a symmetric duopoly the firms can collude using trigger strategies if and only if

$$
\frac{1}{1-\delta} \frac{\Pi^{M}}{2} \geq \Pi^{D}+\frac{1}{1-\delta} \Pi^{N}
$$

where $\delta$ denotes the common discount factor, $\Pi^{M}$ denotes the monopoly profit, $\Pi^{N}$ is the profit in the (Cournot-Nash) equilibrium of the stage game, and $\Pi^{D}$ is the profit of, say, Firm 1 when

\footnotetext{
${ }^{21}$ One can also say that (7) rules out too much overproduction by the inefficient firm.
} 
it deviates from the trigger strategy and produces its (one-period) best response to $x_{2}=\frac{X^{M}}{2}$. Solving (9) gives us a minimum discount rate, $\delta^{*}$, i.e., when $\delta \geq \delta^{*}$ the firms can use trigger strategies to collude. Therefore, $\delta^{*}$ can be considered as a measure of the extent of firms' incentives to collude.

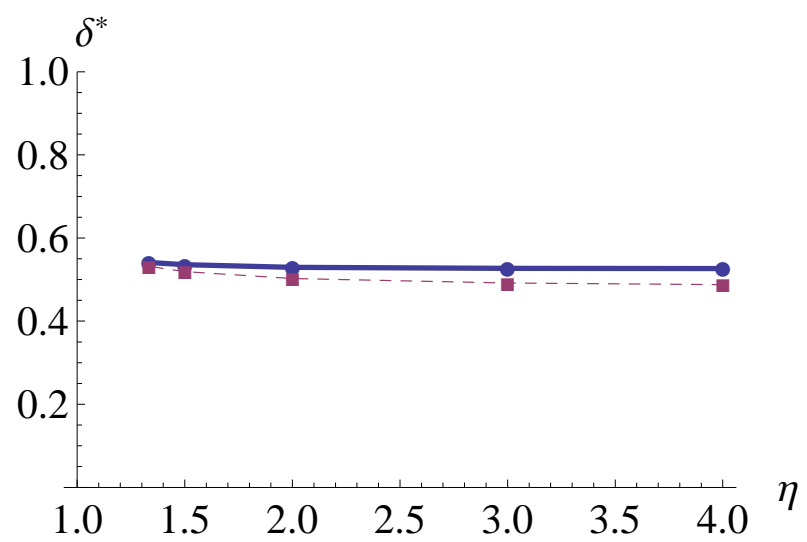

Figure 3: The minimum discount factor under which the firms collude in unregulated Cournot duopoly (solid line) and in a duopoly fully regulated through the revenue contest (dashed line); $P(X)=1 / X^{\eta}$ and $\theta=1 / 2 \eta$

When regulated the firms' incentives to collude may increase because the punishment triggered by deviation becomes more severe under regulation: $\Pi^{N}$ decreases when the duopoly is regulated. ${ }^{22}$ Therefore, when a regulatory scheme does not increase the immediate profit from deviation, $\Pi^{D}$, it will increase the firms' incentives to collude. A nice property of the revenue contest regulation is that under the mechanism $\Pi^{D}$ is larger; sometimes the increase is large enough that the mechanism does not increase the incentives to collude at all.

Lemma 4 In a linear infinitely repeated Cournot duopoly, the revenue contest regulation leads to zero profit but it does not lead to more collusive behavior.

We prove Lemma 4 in the Appendix. In a linear duopoly the two effects (higher immediate profit and higher future penalty) offset each other. In a duopoly with constant elasticity demand $\delta^{*}$ cannot be calculated analytically, (Collie, 2004). When we calculate $\delta^{*}$ numerically we find that the incentives to collude increases under the revenue contest, yet, the increase is small. In Figure 3, we plot $\delta^{*}$ as a function of $\eta$, the solid (dashed) curve shows the minimum discount factor in unregulated (regulated) duopoly. ${ }^{23}$

\footnotetext{
${ }^{22}$ See footnote 14.

${ }^{23}$ As in Collie (2004), we also normalize both $A$ and $c$ by setting both equal to one. As the author discusses,
} 


\section{Discussion and Concluding Remarks}

This paper investigates the effects of regulation through a revenue contest. The mechanism considered here is self-financing and the only role of the government is to observe revenues and make the loser pay a penalty. Hence, it will not involve high transaction costs. With a fully informed regulator it is possible to implement the social optimum in a symmetric Cournot duopoly. Increasing social surplus, through increasing consumers' surplus, and preserving two firm structure and market power are the nice features of the proposed regulation mechanism. In addition, it does not necessarily increase the incentives to collude even though it reduces the profit of each identical firm to zero. Finally, it is easy to implement.

The proposed mechanism may have more appealing features in a multi-period setup where regulator can increase her knowledge by changing revenue contest multiplier and observing changes in output. So a multi-period contest, possibly with a rule that depends on the production level of recent periods, may be an interesting extension of the research considered here. Another area for further research is to analyze a market demand where homogenous goods are seen by consumers as differentiated goods, where coefficients of prices depends on market share of producers. Such an analysis may be useful in explaining market share races among firms, which is something observed in actual market situations.

Acknowledgement: The authors would like to thank Fikret Adaman, İsmail Sağlam, and participants at the Conference on Economic Design (SED 2000), İstanbul, June 22-27, 2000, and PET $200^{7}$ Meeting, Nashville, Tennesee, USA, where earlier versions of this paper was presented, for helpful comments. The paper is in part based on work presented in Evrenk (1999). Partial financial support by Boğaziçi University Research Fund, Project No 97C0103, is gratefully acknowledged.

\section{References}

[1] Anton, J.J., and P.J. Gertler (2004), "Regulation, Local monopolies and Spatial Competition", Journal of Regulatory Economics, Vol. 25, pp. 115-141.

such normalizations does not change the ratio of profits in (9), and, thus, they are innocuous, 
[2] Armstrong, M., and D.E.M. Sappington (2007), "Recent Developments in the Theory of Regulation", Chapter 3 in: (Eds.) Armstrong, M., and R. Porter (2007), Handbook of Industrial Organization, Elsevier, Vol. 3, pp. 1557-1687.

[3] Auriol, E., and J.-J. Laffont (1992), "Regulation by Duopoly", Journal of Economics and Management Strategy, Vol. 1, pp. 507-533.

[4] Auriol, E., and P.M. Picard (2008), "Infrastructure and Public Utilities Proivatization in Developing Countries", The World Bank Economic Review, doi:10.1093/wber/lhn014.

[5] Bagnoli, M., and S. Borenstein (1991), "Carrot and Yardstick Regulation: Enhancing Market Performance with Output Prices", Journal of Regulatory Economics, Vol. 3, pp. $115-36$.

[6] Baron, D., and D. Besanko (1984), "Regulation, Asymmetric Information, and Auditing", Rand Journal of Economics, Vol. 15, pp. 447-470.

[7] Baron, D., and R. Myerson (1982), "Regulating a Monopolist with Unknown Costs", Econometrica, Vol. 50, pp. 553-568.

[8] Collie, D. (2004), "Collusion and the Elasticity of Demand", Economics Bulletin, Vol. 12, pp. 1-6

[9] Demsetz, H. (1968), "Why Regulate Utilities", Journal of Law and Economics, Vol. 11, pp. 55-65.

[10] Dixit, A. (1987), "Strategic Behavior in Contests", American Economic Review, Vol. 77, pp. 891-898.

[11] Evrenk, H. (1999), Regulating Duopolies Through a Revenue Contest, Unpublished Master's Thesis submitted to the Department of Economics, Boğaziçi University, İstanbul.

[12] Freidman, J. (1971), "A Non-Cooperative Equilibrium for Supergames", Review of Economic Studies, Vol. 38, pp. 1-12.

[13] Fershtman, C., and K. L. Judd (1987), "Equilibrium Incentives in Oligopoly", The American Economic Review, Vol. 77, pp. 5-14. 
[14] Gradstein, M. (1995), "Implementation of Social Optimum in Oligopoly", Economic Design, Vol. 1, pp. 319-326.

[15] Koray, S., M.R. Sertel (1987), "Regulating a Cournot Oligopoly by a Pretend-but-Perform Mechanism”, Research Paper ISS/E 87-11, Boğaziçi University, İstanbul.

[16] Koray, S., and M.R. Sertel (1988), "Regulating a Duopoly by a Pretend-but-Perform Mechanism”, in: M. Holler and R. Rees (eds.), Economics of Market Structure, Special Issue of the European Journal of Political Economy, Vol. 4, No. 1, pp. 95-115.

[17] Koray, S., M.R. Sertel (1989), "Meta-Cournotic Equilibrium in Oligopoly: Positive or Regulatory Theory", CARESS Working Paper, No. 89-01-02, University of Pennsylvania.

[18] Krakel, M. (2005), "Strategic Delegation in Oligopolistic Tournaments", Review of Economic Design, Vol. 9, pp. 377-396.

[19] Laffont, J.J. (1996), "Regulation, Privatization, and Incentives in Developing Countries", in: M.G. Quibria and M. Dowling (eds.), Current Issues in Economic Development, Oxford University Press. Hong Kong.

[20] Lewis, T., and D.E.M. Sappington (1988), Regulating a Monopolist with Unknown Demand, American Economic Review, Vol. 78, 986-998.

[21] Mendoza-Contreras, J.E., N. Rickman, and F. Trillas (2008), Regulation by Duopoly Under Political Constraints", typescript, University of Surrey. https://editorialexpress.com/cgibin/conference/download.cgi?db_name=IIOC2009\&paper_id=634.

[22] Sağlam, İ. (1997), Regulatory Mechanisms for Oligopolies, Unpublished Ph.D. Thesis submitted to the Department of Economics, Bilkent University, Ankara.

[23] Sappington, D.E.M. (1983), "Optimal Regulation of a Multiproduct Monopoly with Unknown Technological Capabilities", Bell Journal of Economics, Vol. 14, pp. 453-463.

[24] Schleifer, A. (1985), "A theory of Yardstick Competition", Rand Journal of Economics, Vol. 16, pp. 319-327.

[25] Schmalensee, R. (1976), "A Model of Promotional Competition in Olıgopoly", Review of Economic Studies, Vol. 43, pp. 493-507. 
[26] Sharkey, W.W. (1982), "Existence of Sustainable Prices for Natural Monopoly Outputs", Bell Journal of Economics, Vol. 12, pp. 144-154.

[27] Sklivas, S.D. (1987), "The Strategic Choice of Managerial Incentives", Rand Journal of Economics, Vol. 18, pp. 452-458.

[28] Sobel, J. (1999), "A Reexamination of Yardstick Competition", Journal of Economics and Management Strategy, Vol. 8, pp. 33-60.

[29] Tangerås, T.P. (2002), "Collusion-proof Yardstick Competition", Journal of Public Economics, Vol. 83, pp. 231-254.

[30] Tirole, J. (1998) Industrial Organization, MIT Press Cambridge, MA

[31] Vives, X. (1999), Oligopoly Pricing, MIT Press, Cambridge, MA.

[32] Wang, G.H. (2000), "Regulating an Oligopoly with Unknown Costs", International Journal of Industrial Organization, Vol. 18, pp. 813-825.

[33] Wolinsky, A. (1997), "Regulation of Duopoly: Managed Competition vs Regulated Monopolies", Journal of Economics and Management Strategy, Vol. 6, pp. 821-847.

[34] Zenginobuz, E.ய̈. (1987), Comparing the Performance of a Cournot Oligopoly under Different Forms of Regulation, Unpublished Master's Thesis submitted to the Department of Economics, Boğaziçi University, İstanbul.

\section{Appendix A: Proofs}

Proof of Lemma 1. What we mean by the relevant part of the strategy space is $\left(x_{i}, x_{j}\right)$ such that $P\left(x_{i}+x_{j}\right)>0$. We do not rule out an inverse demand function under which $P(X)=0$ for all $X>\bar{X} \in \mathbb{R}_{+}$, e.g., the linear demand, but, when this is the case, neither firm will choose an output level resulting in an aggregate output level $x_{i}+x_{j} \geq \bar{X}$. Intuitively, this is because the production is costly and driving the price to zero will eliminate any rewards from the contest. More formally, when $x_{i}+x_{j}>\bar{X}$, we always have $\frac{\partial \Pi_{i}^{r}\left(x_{i}, x_{j}, \theta\right)}{\partial x_{i}}=-C_{i}^{\prime}\left(x_{i}\right)<0$. Thus, the relevant part of the strategy space is the part under which $P(X)>0$. Our assumptions $A 1, A 2$, and 
$A 3$ apply to this part of the demand curve and they imply that when $P\left(x_{i}+x_{j}\right)>0$, we have

$$
\partial^{2} \Pi_{i}^{r}\left(x_{i}, x_{j}, \theta\right) /\left(\partial x_{i}\right)^{2}=(2+2 \theta) P^{\prime}(X)+P^{\prime \prime}(X)\left((1+\theta) x_{i}-\theta x_{j}\right)-C_{i}^{\prime \prime}\left(x_{i}\right)<0 .
$$

To see this, note that by $A 4,-C_{i}^{\prime \prime}\left(x_{i}\right) \leq 0$. For the rest, if $(1+\theta) x_{i}-\theta x_{j} \geq 0$, then, by A3, $(2+2 \theta) P^{\prime}(X)+P^{\prime \prime}(X)\left((1+\theta) x_{i}-\theta x_{j}\right)<0$; and, if $(1+\theta) x_{i}-\theta x_{j}<0$, then by A2, $(2+2 \theta) P^{\prime}(X)+P^{\prime \prime}(X)\left((1+\theta) x_{i}-\theta x_{j}\right)<0$.

When (3) holds with equality at $\left(x_{i}, x_{j}\right)$, we have $\frac{\partial B_{i}\left(x_{j}, \theta\right)}{\partial \theta}>0$. By the Implicit Function Theorem, the sign of $\frac{\partial B_{i}\left(x_{j}, \theta\right)}{\partial \theta}$ is the same as the sign of the marginal revenue differential, $\frac{d\left[R_{i}\left(x_{i}, x_{j}\right)-R_{j}\left(x_{i}, x_{j}\right)\right]}{d x_{i}}=P^{\prime}(X)\left(x_{i}-x_{j}\right)+P(X)$; when (3) holds with equality, we have

$$
P^{\prime}(X)\left(x_{i}-x_{j}\right)+P(X)=\frac{-P^{\prime}\left(x_{i}+x_{j}\right) x_{j}+C_{i}^{\prime}\left(x_{i}\right)}{1+\theta}>0 .
$$

Proof of Proposition 1. (Existence) When $\theta=\frac{-P^{\prime}\left(X^{o}\right) X^{o}}{2 P\left(X^{o}\right)}$ and $x_{j}=\frac{X^{o}}{2}$, we have $\frac{\partial \Pi_{i}^{r}\left(\frac{X^{o}}{2}, x_{j}, \theta\right)}{\partial x_{i}}=$ 0 , i.e., for each $i \in\{1,2\}$, we have $\frac{X^{o}}{2}=B_{i}\left(\frac{X^{o}}{2}, \frac{-1}{2 \eta\left(X^{o}\right)}\right)$. Therefore, $\left(\frac{X^{o}}{2}, \frac{X^{o}}{2}\right)$ is a PSNE.

(Uniqueness) First, we show that when the cost functions are symmetric, the game cannot have an asymmetric PSNE. Assume that there exists a PSNE in which, without loss of generality, we have $x_{i}>x_{j} \geq 0$. Then, the first-order conditions imply that

$$
(1+2 \theta) P^{\prime}\left(x_{i}+x_{j}\right)\left(x_{i}-x_{j}\right) \geq C^{\prime}\left(x_{i}\right)-C^{\prime}\left(x_{j}\right) .
$$

$A_{4}$ and $x_{i}>x_{j}$ imply that $C_{i}^{\prime}\left(x_{i}\right)-C_{j}^{\prime}\left(x_{j}\right) \geq 0$ Yet, $P^{\prime}\left(x_{i}+x_{j}\right)<0$ and $x_{i}>x_{j}$ imply that $(1+2 \theta) P^{\prime}\left(x_{i}+x_{j}\right)\left(x_{i}-x_{j}\right)<0$. Contradiction.

Second, we show that there exists at most one symmetric interior equilibrium, $\left(\frac{X^{o}}{2}, \frac{X^{o}}{2}\right)$. The first order conditions at such an equilibrium implies that $(2+2 \theta) P(X)+P^{\prime}(X) X-2 C^{\prime}(X / 2)=0$. The left hand side of this inequality is a continuous function of $X$, and, by $A 3$ and $A 4$, it is decreasing in $X$, i.e., $(3+2 \theta) P^{\prime}(X)+P^{\prime \prime}(X) X-C^{\prime \prime}(X / 2)<0$. Hence, there exists at most one $X>0$ such that $\left(\frac{X}{2}, \frac{X}{2}\right)$ is a PSNE.

Finally, note that $(0,0)$ cannot be a PSNE either, as this would imply $(1+\theta) P(0)-C_{i}^{\prime}(0)<0$, which, in turn, implies that $P(0)-C_{i}^{\prime}(0)<0$, contradicting our assumption that without the regulation only an active Cournot duopoly exists. 
Proof of Proposition 2. Note that the social optimum involves either both firms producing $x_{i}^{o}$ units where $C_{i}^{\prime}\left(x_{i}^{o}\right)=P\left(x_{1}^{o}+x_{2}^{o}\right)$ for each firm $i$, or only the efficient firm producing $\widetilde{x}_{1}^{o}$ where $C_{1}^{\prime}\left(\widetilde{x}_{1}^{o}\right)=P\left(\widetilde{x}_{1}^{o}\right)<C_{2}^{\prime}(0)$.

If at the social optimum each firm $i$ must produce $x_{i}^{o}>0$ units, then (2) should hold with equality for each $i, \frac{\partial \Pi_{i}^{r}\left(x_{i}, x_{j}, \theta\right)}{\partial x_{i}}=0$ for $i \in\{1,2\}$. Subtracting $\frac{\partial \Pi_{2}^{r}\left(x_{i}, x_{j}, \theta\right)}{\partial x_{2}}$ from $\frac{\partial \Pi_{2}^{r}\left(x_{i}, x_{j}, \theta\right)}{\partial x_{2}}$, we find $(1+2 \theta) P^{\prime}\left(x_{1}^{o}+x_{2}^{o}\right)\left(x_{1}^{o}-x_{2}^{o}\right)=0$. Since Firm 1 is more efficient, it should produce more in the social optimum, i.e., $C_{1}^{\prime}\left(x_{1}^{o}\right)=C_{2}^{\prime}\left(x_{2}^{o}\right)$ implies that $x_{1}^{o}>x_{2}^{o}$. Yet, $\theta>0$, and $P^{\prime}(X)<0$. Therefore, there exists no $\theta$ under which each firm $i$ chooses $x_{i}^{o}$ to maximize its profit.

If at the social optimum only the efficient firm must produce $\widetilde{x}_{1}^{o}$ units, where $C_{1}^{\prime}\left(\widetilde{x}_{1}^{o}\right)=$ $P\left(\widetilde{x}_{1}^{o}\right)<C_{2}^{\prime}(0)$ and the inefficient firm must stay out, $x_{2}^{o}=0$, then this output vector cannot be implemented through a revenue contest either. Because, when the output vector is $\left(\widetilde{x}_{1}^{o}, 0\right)$ the less efficient Firm 2 is making a loss (although, it has no fixed cost). Then, Firm 2 would leave the market and the contest altogether.

Proof of Lemma 2. Once again, in an asymmetric equilibrium in which $0 \leq x_{1}^{*}(\theta) \leq x_{2}^{*}(\theta)$, the first order conditions imply that $(1+2 \theta) P^{\prime}\left(x_{1}^{*}(\theta)+x_{2}^{*}(\theta)\right)\left(x_{1}^{*}(\theta)-x_{2}^{*}(\theta)\right) \leq C_{1}^{\prime}\left(x_{1}^{*}(\theta)\right)-$ $C_{2}^{\prime}\left(x_{2}^{*}(\theta)\right)$. Since Firm 1 is more efficient, by $A_{4}$ we have $C_{2}^{\prime}\left(x_{1}^{*}(\theta)\right) \leq C_{2}^{\prime}\left(x_{2}^{*}(\theta)\right)$. Therefore, $C_{1}^{\prime}\left(x_{1}^{*}(\theta)\right)-C_{2}^{\prime}\left(x_{2}^{*}(\theta)\right)<0$. But, $P^{\prime}(X)<0$ and $x_{1}^{*}(\theta) \leq x_{2}^{*}(\theta)$. Contradiction.

Proof of Lemma 3. Since both firms are producing, $\frac{\partial \Pi_{1}^{r}\left(x_{1}^{*}(\theta), x_{2}^{*}(\theta), \theta\right)}{\partial x_{1}}=0$ and $\frac{\partial \Pi_{2}^{r}\left(x_{1}^{*}(\theta), x_{2}^{*}(\theta), \theta\right)}{\partial x_{2}}=$ 0 . Differentiating these two equations with respect to $\theta$, we find that

$$
\left[\begin{array}{cc}
\frac{\partial^{2} \Pi_{1}^{r}\left(x_{1}^{*}(\theta), x_{2}^{*}(\theta), \theta\right)}{\left(\partial x_{1}\right)^{2}} & \frac{\partial^{2} \Pi_{1}^{r}\left(x_{1}^{*}(\theta), x_{2}^{*}(\theta), \theta\right)}{\partial x_{1} \partial x_{2}} \\
\frac{\partial^{2} \Pi_{2}^{r}\left(x_{1}^{*}(\theta), x_{2}^{*}(\theta), \theta\right)}{\partial x_{2} \partial x_{1}} & \frac{\partial^{2} \Pi_{2}^{r}\left(x_{1}^{*}(\theta), x_{2}^{*}(\theta), \theta\right)}{\left(\partial x_{2}\right)^{2}}
\end{array}\right]\left[\begin{array}{c}
\frac{d x_{1}^{*}(\theta)}{d \theta} \\
\frac{d x_{2}^{*}(\theta)}{d \theta}
\end{array}\right]=\left[\begin{array}{c}
-\frac{\partial^{2} \Pi_{1}^{r}\left(x_{1}^{*}(\theta), x_{2}^{*}(\theta), \theta\right)}{\partial x_{1} \partial \theta} \\
-\frac{\partial^{2} \Pi_{2}^{r}\left(x_{1}^{*}(\theta), x_{2}^{*}(\theta), \theta\right)}{\partial x_{2} \partial \theta}
\end{array}\right] .
$$

That is, $\frac{d x_{i}^{*}(\theta)}{d \theta}=\frac{\left|D_{i}\right|}{|J|}$ where $J$ is the Jacobian matrix and $D_{i}$ is the $2 \mathrm{x} 2$ matrix that is obtained when the $i^{\prime}$ th column of the Jacobian is replaced by the vector on the left-hand-side of (10).

Subtracting the first column from the second one and the dividing the first row by $C_{1}^{\prime \prime}\left(x_{1}^{*}\right)-$ $(1+2 \theta) P^{\prime}\left(X^{*}\right)$ and the second row by $C_{2}^{\prime \prime}\left(x_{2}^{*}\right)-(1+2 \theta) P^{\prime}\left(X^{*}\right)$, one can show that $|J|>0$ if and only if

$$
1>\frac{P^{\prime}\left(X^{*}\right)+P^{\prime \prime}\left(X^{*}\right)\left(x_{1}^{*}+\theta\left(x_{1}^{*}-x_{2}^{*}\right)\right)}{C_{1}^{\prime \prime}\left(x_{1}^{*}\right)-(1+2 \theta) P^{\prime}\left(X^{*}\right)}+\frac{P^{\prime}\left(X^{*}\right)+P^{\prime \prime}\left(X^{*}\right)\left(x_{2}^{*}+\theta\left(x_{2}^{*}-x_{1}^{*}\right)\right)}{C_{2}^{\prime \prime}\left(x_{2}^{*}\right)-(1+2 \theta) P^{\prime}\left(X^{*}\right)}
$$

Rewriting [11], we have $|J|>0$ if and only if $C_{1}^{\prime \prime}\left(x_{1}^{*}\right) C_{2}^{\prime \prime}\left(x_{2}^{*}\right)+\left((1+2 \theta) P^{\prime}\left(X^{*}\right)\right)^{2}>C_{2}^{\prime \prime}\left(x_{2}^{*}\right)(A+$ 
$\left.(1+2 \theta) P^{\prime}\left(X^{*}\right)\right)+C_{1}^{\prime \prime}\left(x_{1}^{*}\right)\left(B+(1+2 \theta) P^{\prime}\left(X^{*}\right)\right)-(1+2 \theta) P^{\prime}\left(X^{*}\right)\left(2 P^{\prime}\left(X^{*}\right)+P^{\prime \prime}\left(X^{*}\right) X^{*}\right)$ where

$$
\begin{aligned}
& A=P^{\prime}\left(X^{*}\right)+P^{\prime \prime}\left(X^{*}\right)\left(x_{1}^{*}+\theta\left(x_{1}^{*}-x_{2}^{*}\right)\right), \\
& B=P^{\prime}\left(X^{*}\right)+P^{\prime \prime}\left(X^{*}\right)\left(x_{2}^{*}+\theta\left(x_{2}^{*}-x_{1}^{*}\right)\right) .
\end{aligned}
$$

By $A 4, C_{i}^{\prime \prime}\left(x_{i}^{*}\right) \geq 0$, and, thus, $C_{1}^{\prime \prime}\left(x_{1}^{*}\right) C_{2}^{\prime \prime}\left(x_{2}^{*}\right)+\left((1+2 \theta) P^{\prime}\left(X^{*}\right)\right)^{2}>$. By $A 3$, each of the terms $A+(1+2 \theta) P^{\prime}\left(X^{*}\right), B+(1+2 \theta) P^{\prime}\left(X^{*}\right)$, and $-(1+2 \theta) P^{\prime}\left(X^{*}\right)\left(2 P^{\prime}\left(X^{*}\right)+P^{\prime \prime}\left(X^{*}\right) X^{*}\right)$ are less than zero. Hence, $|J|>0$.

We have, $\frac{d X^{*}(\theta)}{d \theta}=\frac{d x_{1}^{*}(\theta)}{d \theta}+\frac{d x_{2}^{*}(\theta)}{d \theta}>0$ if and only if $\left|D_{1}\right|+\left|D_{2}\right|>0$ where these determinants are given by $\left|D_{1}\right|=-\left(P\left(X^{*}\right)+P^{\prime}\left(X^{*}\right)\left(x_{1}^{*}-x_{2}^{*}\right)\right)\left((1+2 \theta) P^{\prime}\left(X^{*}\right)+B-C_{2}^{\prime \prime}\left(x_{2}^{*}\right)\right)+\left(P\left(X^{*}\right)+\right.$ $\left.P^{\prime}\left(X^{*}\right)\left(x_{2}^{*}-x_{1}^{*}\right)\right) A$, and $\left|D_{2}\right|=\left(P\left(X^{*}\right)+P^{\prime}\left(X^{*}\right)\left(x_{1}^{*}-x_{2}^{*}\right)\right) B-\left(P\left(X^{*}\right)+P^{\prime}\left(X^{*}\right)\left(x_{2}^{*}-x_{1}^{*}\right)\right)((1+$ $\left.2 \theta) P^{\prime}\left(X^{*}\right)+A-C_{1}^{\prime \prime}\left(x_{1}^{*}\right)\right)$. The sum, $\left|D_{1}\right|+\left|D_{2}\right|$, is equal to $-\left(P\left(X^{*}\right)+P^{\prime}\left(X^{*}\right)\left(x_{1}^{*}-x_{2}^{*}\right)\right)((1+$ $\left.2 \theta) P^{\prime}\left(X^{*}\right)-C_{2}^{\prime \prime}\left(x_{2}^{*}\right)\right)-\left(P\left(X^{*}\right)+P^{\prime}\left(X^{*}\right)\left(x_{2}^{*}-x_{1}^{*}\right)\right)\left((1+2 \theta) P^{\prime}\left(X^{*}\right)-C_{1}^{\prime \prime}\left(x_{1}^{*}\right)\right)$. To see that this expression is always positive note that (i) as we show in the proof of Lemma 1, we have $P\left(X^{*}\right)+P^{\prime}\left(X^{*}\right)\left(x_{i}^{*}-x_{j}^{*}\right)>0$, and (ii) the cost functions are convex, therefore, we have $(1+2 \theta) P^{\prime}\left(X^{*}\right)-C_{1}^{\prime \prime}\left(x_{1}^{*}\right)<0$. Hence $\frac{d X^{*}(\theta)}{d \theta}>0$.

Proof of Lemma 4. Consider the following trigger strategy for a duopolist in a market regulated through revenue contest. Produce half of the monopoly quantity, $\frac{a-c}{4}$, in the first period. In the $t^{t h}$ period produce $\frac{a-c}{4}$ if both firms have produced $\frac{a-c}{4}$ in each of the previous periods; otherwise, produce the regulated Cournot quantity, $\frac{a-c}{2}$. The profit to one firm when both produce $\frac{a-c}{4}$ is $\frac{(a-c)^{2}}{8}$. The profit to one firm when both produce $\frac{a-c}{2}$ is zero. Finally if one of the firms deviates, its best response to $\frac{a-c}{4}$ is $\frac{5(a-c)}{8}$, with an associated profit of $\frac{17(a-c)^{2}}{64}$. Evaluating (9) at these values, we find that under the revenue contest $\delta^{*}=\frac{9}{17}$. It is well known that, Vives (1999: 307), in the classical linear Cournot duopoly with symmetric cost, we have $\delta^{*}=\frac{9}{17}$.

\section{Appendix B: When do we have $\frac{d x_{1}^{*}(\theta)}{d \theta}<0$ ?}

Here we examine the conditions under which the efficient firm's output may decrease in $\theta$. Using the Implicit function theorem, one can show that, in equilibrium, the slope of firm $i$ 's best-response function has the same sign as $P^{\prime}\left(X^{*}(\theta)\right)+P^{\prime \prime}\left(X^{*}(\theta)\right)\left(x_{i}^{*}(\theta)+\left(x_{i}^{*}(\theta)-x_{j}^{*}(\theta)\right) \theta\right)$. Therefore, the inefficient firm's best-response function is always downward sloping while whether 
the efficient firm's best-response is increasing or decreasing cannot be determined at this level of generality. Still, we show in the Proof of Lemma 3 that the Jacobian of minus marginal profits are positive at all interior equilibria, therefore at any interior equilibrium, in $\left(x_{2}, x_{1}\right)$ space the slope of $B_{1}($.$) is always larger than the slope of B_{2}(.) .{ }^{24}$ By Lemma 1 we know that when $\theta$ increases both reaction functions are going to shift out. Therefore we have two possibilities: (i) when, as in Figure 4.a, the efficient firm's best-response function is increasing in the inefficient firm's output, $x_{2}$, at the new equilibrium the efficient firm's output will always increase, $\frac{d x_{1}^{*}(\theta)}{d \theta}>$ 0 ; and (ii) when, as in Figure 4.b, the efficient firm's best-response is decreasing in $x_{2}$, at the new equilibrium the efficient firm may produce less, $\frac{d x_{1}^{*}(\theta)}{d \theta}<0$ is possible. ${ }^{25}$

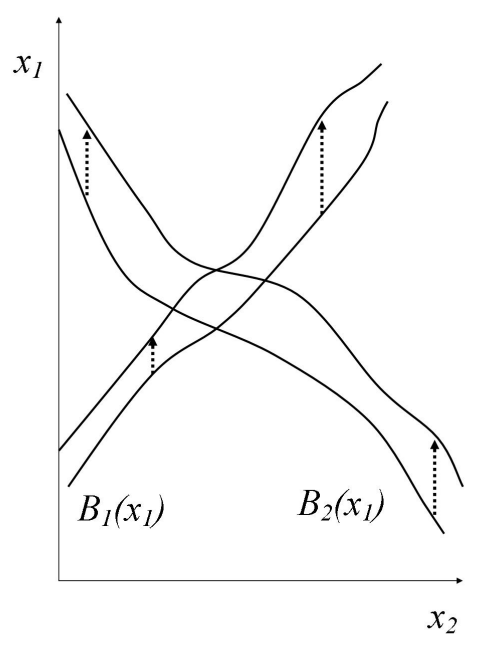

(a)

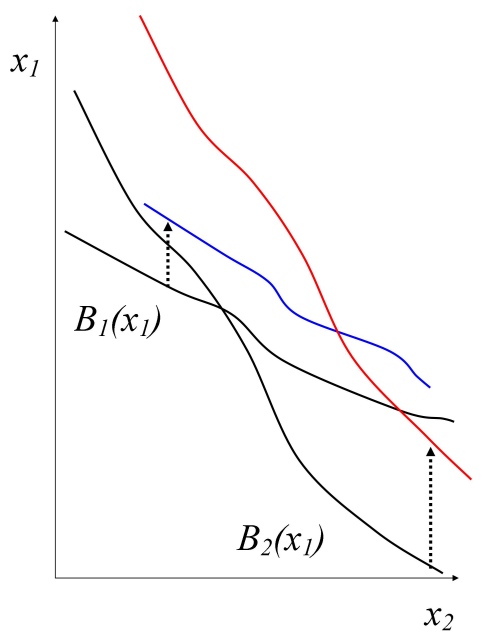

(b)

Figure 4: If, as in panel (a), the efficient firm's best-response function, $B_{1}\left(x_{2}, \theta\right)$, is increasing in $x_{2}$, then $x_{1}^{*}(\theta)$ always increases in $\theta$. If, as in panel (b), $B_{1}\left(x_{2}, \theta\right)$ is decreasing in $x_{2}$, then $x_{1}^{*}(\theta)$ may decrease in $\theta$.

Intuitively, when the output levels are strategic substitutes, as in Figure 4.b, an increase in the contest parameter has two effects: a direct effect, the firm produces more to increase the prize, and an indirect effect (the competitor, too, increases its output reducing the marginal

\footnotetext{
${ }^{24}$ It is worth noting that $|J|>0$ also implies that if an interior equilibrium exists, then it is unique. This follows from Poincaré-Hopf Index Theorem, see Kolstad and Mathiesen (1987) and the discussion in Vives (2001: 98).

${ }^{25}$ If $\frac{\partial B_{1}(.)}{\partial x_{2}}=0$, then, we have $\frac{d x_{1}^{*}(\theta)}{d \theta}=0$. Under whis, (6) always hold.
} 
revenue of the efficient firm) produces less to keep price higher. Let us note the following two points: (i) the indirect effect is not necessarily larger than the direct effect ${ }^{26}$, and (ii) even when the indirect effect is larger than the direct effect, this does not necessarily mean that the social surplus decreases in $\theta$, i.e., for $\frac{d S S\left(x_{1}^{*}(\theta), x_{2}^{*}(\theta)\right)}{d \theta}<0$ to hold, $\frac{d x_{1}^{*}(\theta)}{d \theta}<0$ is not a sufficient condition.

\section{Appendix C: Solutions for Examples 1 and 2}

Remark 1: For both examples if the monopoly outcome is not a PSNE in the unregulated market, then it cannot be a PSNE under revenue contest regulation.

To see the point made in Remark 1, note that the monopoly outcome is not a PSNE in the unregulated market if and only if $\frac{\partial \pi_{2}\left(0, X_{M}\right)}{\partial x_{2}}>0$, i.e., $P\left(X_{M}\right)-C_{2}^{\prime}(0)>0$ where $X^{M}$ is implicitly defined by $P\left(X_{M}\right)+P^{\prime}\left(X_{M}\right) X_{M}-C_{1}^{\prime}\left(X_{M}\right)=0$. In the same market under the revenue contest regulation, monopoly is not an equilibrium, when we have $(1+\theta) P(\widetilde{X})-\theta P(\widetilde{X}) \widetilde{X}-C_{2}^{\prime}(0)<0$ where $\tilde{X}>X_{M}$ is implicitly defined by $(1+\theta) P(\tilde{X})+(1+\theta) P^{\prime}(\tilde{X}) \tilde{X}-C_{1}^{\prime}(\tilde{X})=0$. A sufficient condition to rule out the possibility that revenue contest leads to a monopoly is $-(1+2 \theta) P^{\prime}(\widetilde{X}) \widetilde{X}>-P^{\prime}\left(X_{M}\right) X_{M}$, (by convexity of the cost function, we have $C_{1}^{\prime}(\tilde{X}) \geq$ $\left.C_{1}^{\prime}\left(X_{M}\right)\right)$. Translating this condition into the markets we consider in Examples 1 and 2, we have:

- Under the constant elasticity demand $\widetilde{X}=\left(\frac{(1+\theta)\left(1-\frac{1}{\eta}\right) A}{C_{1}^{\prime}(\tilde{X})}\right)^{\eta}>X_{M}=\left(\frac{\left(1-\frac{1}{\eta}\right) A}{C_{1}^{\prime}\left(X_{M}\right)}\right)^{\eta}$, and therefore

$$
-(1+2 \theta) P(\widetilde{X}) \widetilde{X}=\frac{(1+2 \theta)}{\eta}\left(\frac{(1+\theta)\left(1-\frac{1}{\eta}\right) A}{C_{1}^{\prime}(\widetilde{X})}\right)^{-1}>-P^{\prime}\left(X_{M}\right) X_{M}=\frac{1}{\eta}\left(\frac{\left(1-\frac{1}{\eta}\right) A}{C_{1}^{\prime}\left(X_{M}\right)}\right)^{-1} .
$$

- Under the linear demand, $P^{\prime}(X) X=-X$, therefore, we always have $-(1+2 \theta) P^{\prime}(\tilde{X}) \tilde{X}>$ $P^{\prime}\left(X_{M}\right) X_{M}$

\footnotetext{
${ }^{26}$ To see this point, simply note that when the efficient (inefficient) firm's best response function shifts more (less) than it did in Figure 1.b, then, we have $\frac{d x_{1}^{*}(\theta)}{d \theta}>0$.
} 


\subsection{Equilibrium under constant elasticity demand}

When $P(X)=X^{-\eta}$, the first order condition, (3), can be written as

$$
x_{i} \geq \frac{\left(X^{\frac{-1}{\eta}}-c_{i}\right) x_{i}+\frac{\theta}{\eta} X^{\frac{-1}{\eta}-1} x_{j}}{\left(1+\frac{\theta}{\eta}\right) X^{\frac{-1}{\eta}-1}} .
$$

As long as the participation constraints hold for both firms, we have $X^{\frac{-1}{\eta}}-c_{i}>0$ for both firms and, thus, (12) holds as an equality. In equilibrium, we have

$$
X^{*}=\left(\frac{2(1+\theta)-\frac{1}{\eta}}{c_{1}+c_{2}}\right)^{\eta} \text { and } x_{i}^{*}=\frac{1}{2}\left(\frac{\left(c_{j}-c_{i}\right) \eta}{(1+2 \theta)}\left(X^{*}\right)^{\frac{1+\eta}{\eta}}+X^{*}\right) .
$$

By Remark 1, this is the unique PSNE of the game. Next, using (13), we show that $\frac{d x_{1}^{*}}{d \theta}>0$. We can write $\frac{d x_{1}^{*}}{d \theta}$ as

$$
\frac{1}{2}\left((1+\eta) \frac{\left(c_{2}-c_{1}\right)}{(1+2 \theta)}\left(X^{*}\right)^{\frac{1}{\eta}}+1\right) \frac{d X^{*}}{d \theta}-\left(\frac{\left(c_{2}-c_{1}\right) \eta}{(1+2 \theta)^{2}}\left(X^{*}\right)^{\frac{1+\eta}{\eta}}\right.
$$

where $\frac{d X^{*}}{d \theta}=\eta\left(X^{*}\right)^{\frac{\eta-1}{\eta}} \frac{2}{\left(c_{2}+c_{1}\right)}>0$. Therefore,

$$
\frac{d x_{1}^{*}}{d \theta}>0 \Longleftrightarrow \frac{\left(c_{2}+c_{1}\right)}{\left(c_{2}-c_{1}\right)}>\frac{2(1+\theta)-\frac{1}{\eta}}{1+2 \theta}\left(\frac{2(1+\theta)-\frac{1}{\eta}}{1+2 \theta}-(1+\eta)\right) .
$$

We know that $\frac{\left(c_{2}+c_{1}\right)}{\left(c_{2}-c_{1}\right)}>0$. In $(14)$, the term $\frac{2(1+\theta)-\frac{1}{\eta}}{1+2 \theta}$ is always positive (as $\left.\frac{1}{\eta}<1\right)$, but it is decreasing in $\theta$, therefore $\frac{2(1+\theta)-\frac{1}{\eta}}{1+2 \theta}$ is largest when $\theta=0$. But, even at $\theta=0$, we have $2-\frac{1}{\eta}-(1+\eta)=1-\frac{1}{\eta}-\eta<0$. Hence, under constant elasticity demand, we have $\frac{d x_{1}^{*}(\theta)}{d \theta}>0$.

Evaluating (12) at $\theta=0$, we can show that when the Cournot duopoly is unregulated, the less efficient firm's profit is non-negative if and only if,

$$
\left(\frac{c_{1}+c_{2}}{2-\frac{1}{\eta}}-c_{2}\right) \frac{1}{2}\left(\frac{c_{1}+c_{2}}{2-\frac{1}{\eta}}\right)^{-\eta}\left(1+\frac{\left(c_{1}-c_{2}\right) \eta\left(2-\frac{1}{\eta}\right)}{c_{1}+c_{2}}\right) \geq 0
$$

In (15), $\frac{c_{1}+c_{2}}{2-\frac{1}{\eta}}-c_{2} \geq 0$ if and only if $c_{1} \geq\left(1-\frac{1}{\eta}\right) c_{2}$; the term $1+\frac{\left(c_{1}-c_{2}\right) \eta\left(2-\frac{1}{\eta}\right)}{c_{1}+c_{2}} \geq 0$ if and only if $c_{1} \geq\left(1-\frac{1}{\eta}\right) c_{2}$. So, in the unregulated Cournot duopoly a unique interior PSNE exists if and 
only if

$$
c_{1} \geq\left(1-\frac{1}{\eta}\right) c_{2}
$$

This interior PSNE is the unique PSNE of the game as the condition that ensures no corner equilibrium exists in unregulated Cournot duopoly, $P\left(X_{M}\right)-C_{2}^{\prime}(0)>0 \Leftrightarrow c_{1} \geq \frac{\left(1-\frac{2}{\eta}\right)}{\left(1-\frac{1}{\eta}\right)} c_{2}$ will hold whenever (16) holds.

\subsection{Equilibrium under linear demand}

When $P(X)=a-X$, the best-response functions are as follows,

$$
B_{i}\left(x_{j}, \theta\right)=\frac{(1+\theta) a-x_{j}-c_{i}}{2(1+\theta)} .
$$

Note that the best response functions for each firm are linear and downward sloping. The resulting unique equilibrium output levels are given by

$$
x_{i}^{*}(\theta)=\frac{(1+2 \theta)\left((1+\theta) a-2(1+\theta) c_{i}+c_{j}\right.}{(1+2 \theta)(3+2 \theta)} .
$$

The less efficient firm's equilibrium profit is given by

$$
\frac{\left(a+c_{1}-2 c_{2}\right)^{2}+\left(3\left(a+c_{1}\right)^{2}-\left(13 a+4 c_{1}\right) c_{2}+5 c_{2}^{2}\right) \theta+2\left(\left(a+c_{1}\right)^{2}-6 a c_{2}+c_{2}^{2}\right)-4 \theta a c_{2}}{(1+2 \theta)(3+2 \theta)^{2}} .
$$

